\title{
AN EXPERIMENTAL STUDY ON THE ABSORPTION CAPACITY \& REUSABILITY OF COTTON \& THE EFFECT OF SALINITY ON CRUDE OIL FRACTIONS ON SEA WATER (BAY OF BENGAL)
}

\author{
Jyothi Meher Nori ${ }^{1}$, B.N.S. Anurag ${ }^{2}$, V.Ananth Kumar Thimmarusu ${ }^{3}$ \\ ${ }^{I}$ Department of Chemical Engineering, CBIT, Telangana, India \\ ${ }^{2}$ Department of Chemical Engineering, CBIT, Telangana, India \\ ${ }^{3}$ Associate. Prof., M.Tech. (Chem. Engg.), CBIT, Telangana, India
}

\begin{abstract}
Crude oil is the most valuable component in today's ever- demanding world. When this crude oil is spilled, there would be a potential to cause significant environmental impact posing a serious threat to aquatic and human lives. Due to this very reason there is a drastic need to recover spilled crude oil \& oil spill cleanup is characterized to be one of the most challenging tasks for engineers in today's ever-growing modern world. The previous methods used for the removal of oil from the spillage sites were oil booms, dispersants, skimmers and sorbents. These techniques were very expensive and showed very low adsorption capacity. To curb this very problem one can use the gift of nature provided to mankind, the most abundantly used material on mother earth, cotton, a highly absorbent material which is able to sop up 30 times its own weight in oil.
\end{abstract}

About our work: A preliminary attempt has been made by us in our laboratory to study in detail the absorption and adsorption capacity (at room temperature $22^{\circ} \mathrm{C}$ ), effect of salinity and reusability factor of cotton on various fractions of crude oil on Sea Water (Bay of Bengal) using various types of cotton (seeded cotton, mattress cotton, machinery/threaded cotton and clinical cotton) and readily available fuels. All the results obtained here have been recorded while performing the experiments in our laboratory and are based on our own original research. These experimental results obtained have been presented. Along with this a statistical comparison between the adsorption capacities of this latest method used for the removal of crude oil fractions to the methods previously used.

Keywords - crude oil, oil spills, cotton, adsorption, salinity, reusability, recovered oil. $* * *$

\section{INTRODUCTION}

An oil spill occurs when liquid petroleum is released into the surrounding environment, especially in seas and oceans during the transportation. This may occur due to human activity or environmental factors such as hurricanes, tsunamis and other such similar phenomenon.

The below bar chart shows the quantity of crude oil spilled in the seas and ocean water from the years $1990-2005$ due to accidental oil spills. These oil spills not only cause harm to marine animals, but they also cause a lot of pollution which is very difficult to control.

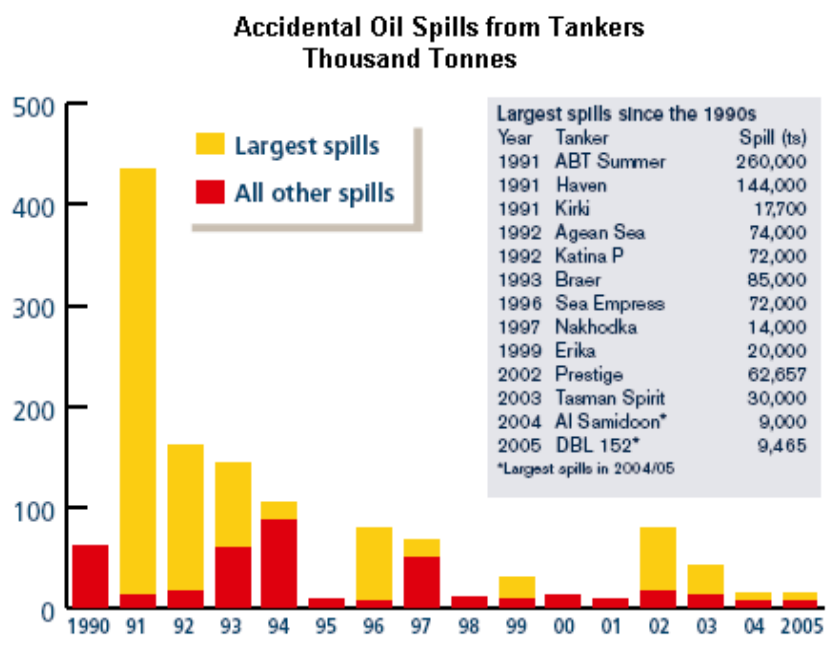

Source: Intertanko Tanker Facts 2006, http://www.intertanko.com/about/annualreports/2005/5.html

Fig-1: Amount of oil spilled (1990-2005) 
To recover this spilled oil on the water surface there are many primitive methods used. Some of these methods are discussed below.

1. Manual Cleanup: Manual cleanup is when workers are placed and with the help of shovels, rakes and gloves oil is collected. This process requires heavy machinery which is very expensive and is used in the areas where spillage is high.

2. Gelling Agents: Gelling agents solidify spilled oil so that it can be easily collected with the help of nets or suction devices.

3. Surface Dispersants: Surface dispersants are sprayed on the oil with the help of boats and aircrafts. These chemical dispersants reduce the oil slicks into droplets that can easily be degraded by the use of bacteria.

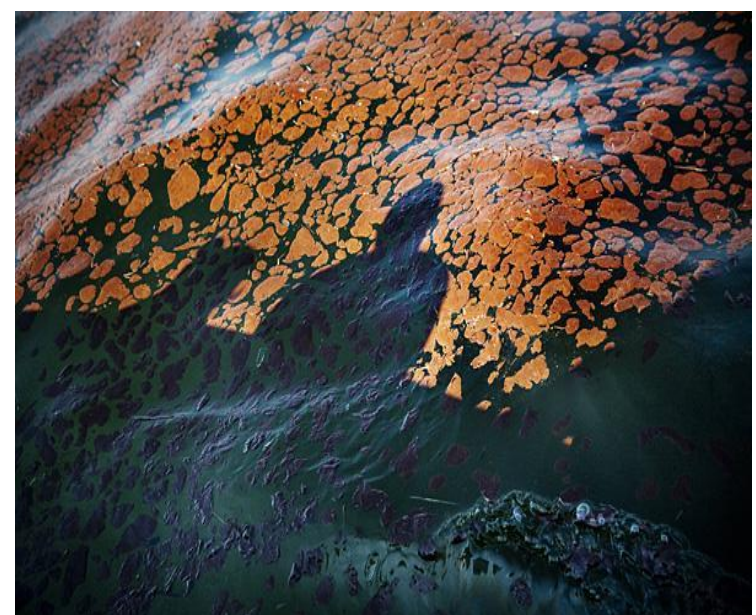

Fig-2: Surface Dispersants sprayed into the waters.

4. Booms and skimmers: Booms and skimmers remove the spilled oil from the surface.

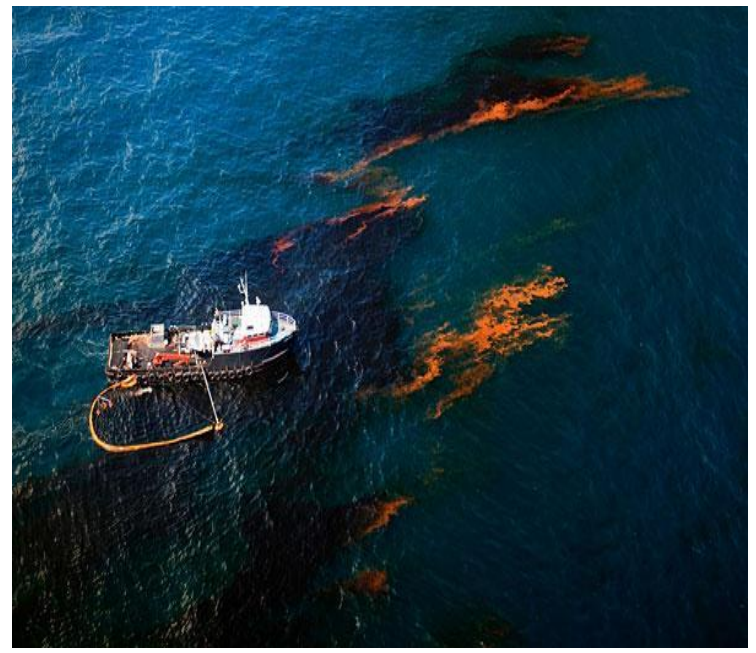

Fig-3: Cleaning up of oil using booms and skimmers

\section{USE OF COTTON - THE INWORD FOR OIL SPILLS}

In this experiment Sea water from Bay of Bengal (Machilipatnam beach, Andhra Pradesh) has been collected and oil has been taken which is obtained from various fractions of crude oil (petrol, diesel, kerosene mixed in the ratio of $1: 1: 1)$. A detailed experimental study has been conducted. The experimental results obtained have been noted down and these values been presented.

\subsection{Physical Properties}

According to laboratory analysis conducted on sea water and distilled water the following properties have been obtained:

\section{Distilled Water:}

pH: 7.0

Density: $1 \mathrm{~g} / \mathrm{cc}$

Specific gravity: 1

Turbidity: 0 NTU

Salinity: 0 grams of salt/ liter of water

\section{Sea Water:}

$\mathrm{pH}: 8.2$

Density: $1.015 \mathrm{~g} / \mathrm{cc}$

Specific gravity: 1.015

Turbidity: 120 NTU

Salinity: $37.7 \mathrm{gm}$ of salt/ liter of seawater

\section{ABSORPTION CAPACITY OF COTTON}

To determine the amount of crude oil fractions that cotton can absorb, the absorption test had been conducted as follows:

\section{Materials used for this Experiment}

For this experiment 6 liter of distilled water and 6 liter of seawater have been used along with $500 \mathrm{ml}$ of mixed fuel has been taken (i.e., petrol, diesel and kerosene mixed in the ratio $1: 1: 1$ ). Cottons of different grades (seeded cotton, mattress cotton, machinery/threaded cotton and clinical cotton) have been taken as shown below: 


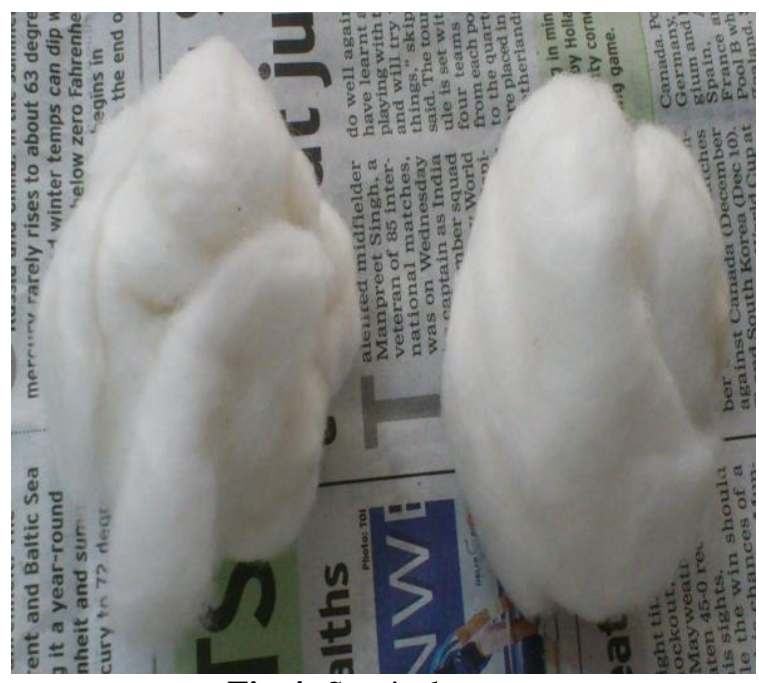

Fig-4: Surgical cotton

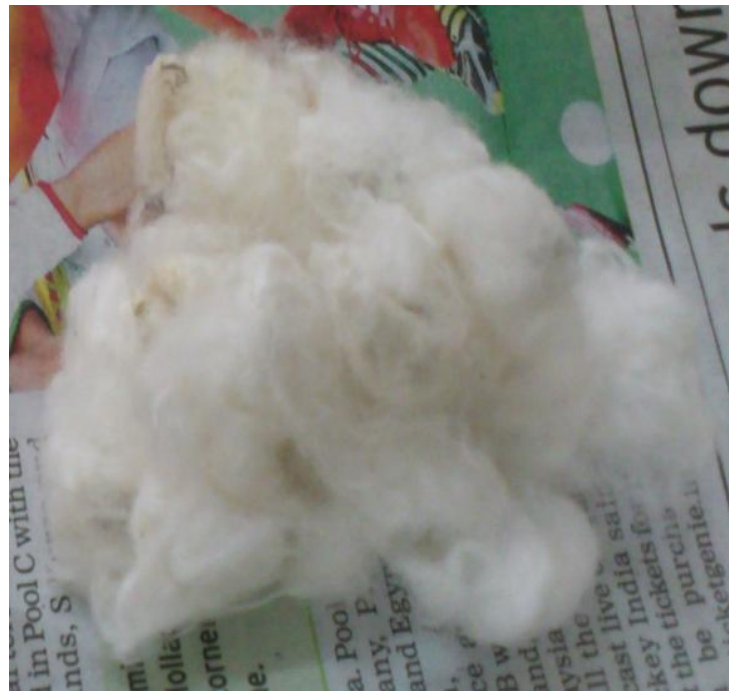

Fig-5: Seeded cotton

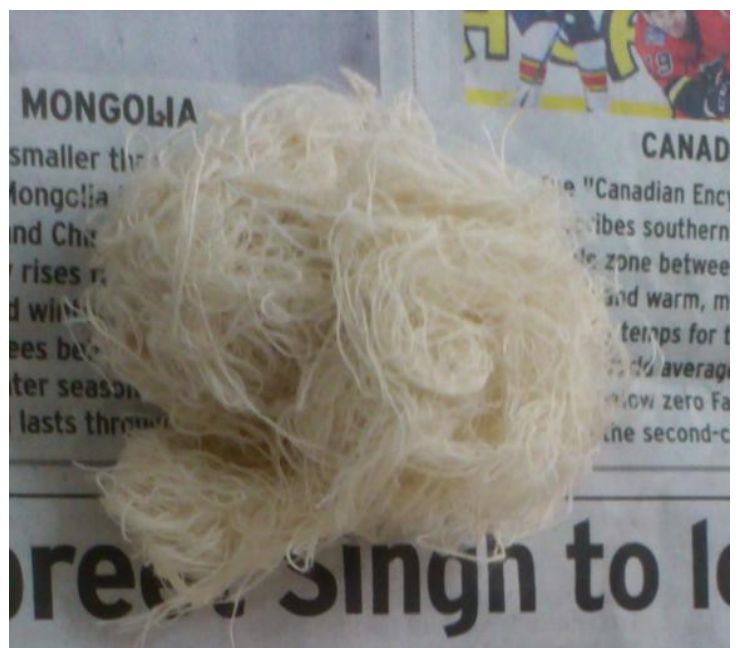

Fig-6: Machinery cotton/ threaded cotton

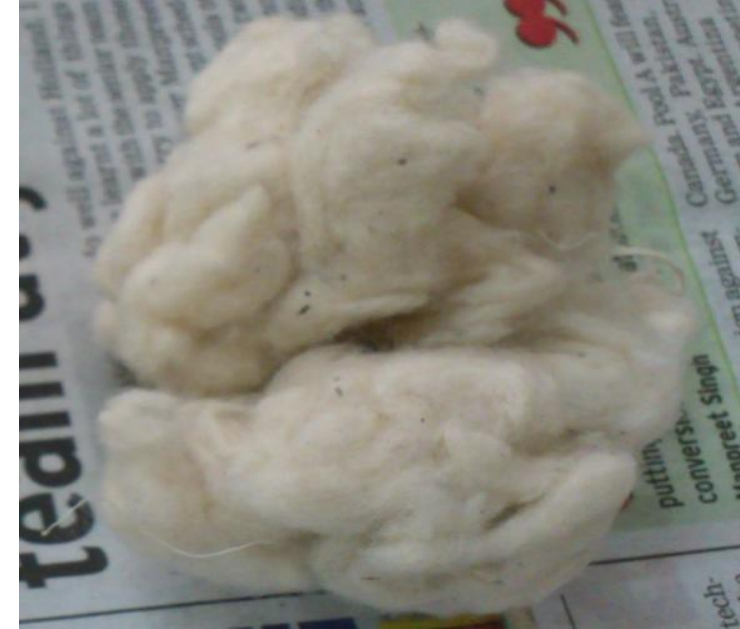

Fig-7: Mattress cotton

The apparatus used here are glass rod, beakers, jug, $1000 \mathrm{ml}$ measuring jar and $30 \mathrm{ml}$ measuring jar.

\section{Assumptions:}

1. The experiments are conducted at room temperature.

2. The volatilities of the oilin a mixture (fuel + water) are taken as negligible at room temperature.

3. The condition is static not wavy as in actual sea.

4. Wind velocities of the mixture are negligible.

5. In trial-1 for all species of cotton the sample was divided into two big pieces each assumed to be spheres amounting to a total surface area of 91.9035 sq.cm.

6. In trial-2 for all species of cotton the sample was divided into ten small pieces assumed to be cuboidal in shape amounting to a total surface area of $124.41 \mathrm{sq} . \mathrm{cm}$.

7. In trial-3 for all species of cotton the sample was divided into one single flat cylindrical disc having a thickness of $0.8 \mathrm{~cm}$ and amounting to a total surface area of $32.86 \mathrm{sq} . \mathrm{cm}$.

\subsection{Experimental Procedure}

$500 \mathrm{ml}$ of Sea water is taken in a confined area using a measuring jug of $1000 \mathrm{ml}$. To this $30 \mathrm{ml}$ of the fraction of crude oil (Petrol, Diesel, Kerosene mixed in equal ratios) was added. A known quantity $(2.5 \mathrm{gm})$ of cotton of different grades as mentioned were taken and put in the mixture and was allowed to be in contact with the mixture for a constant time of 3 minutes.

A similar experimental procedure has been conducted on distilled water for reference. 


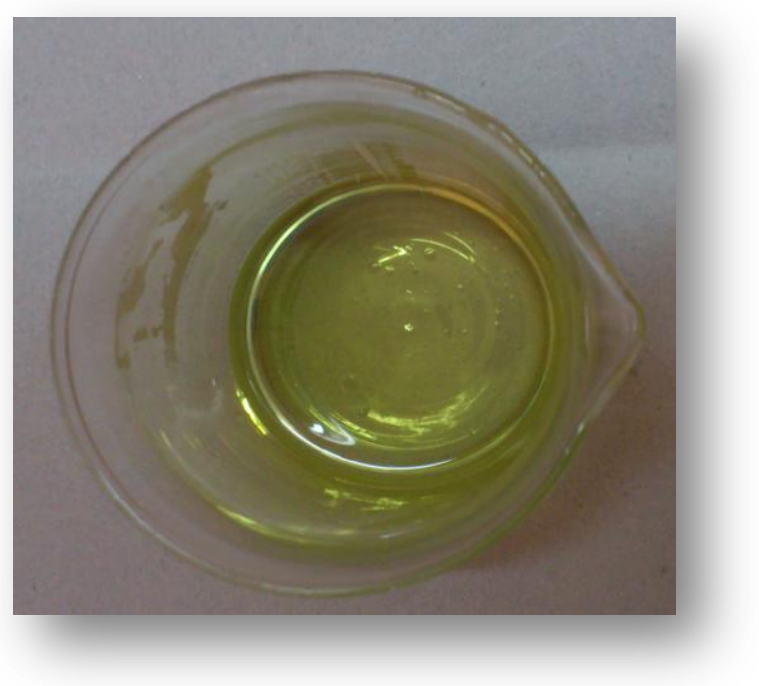

Fig-8: Mixed fuel

\section{Graphical Representation}

The experiments have been conducted as explained above and the results obtained have been presented in the graphs.

The first 4 graphs (i.e. Fig9 - Fig12) show a comparative study about the amount of oil that has been absorbed by different types of cotton in seawater and distilled water.

The fifth graph (i.e. Fig13) shows the cumulative oil adsorption capacities of all 4 cotton samples taken.

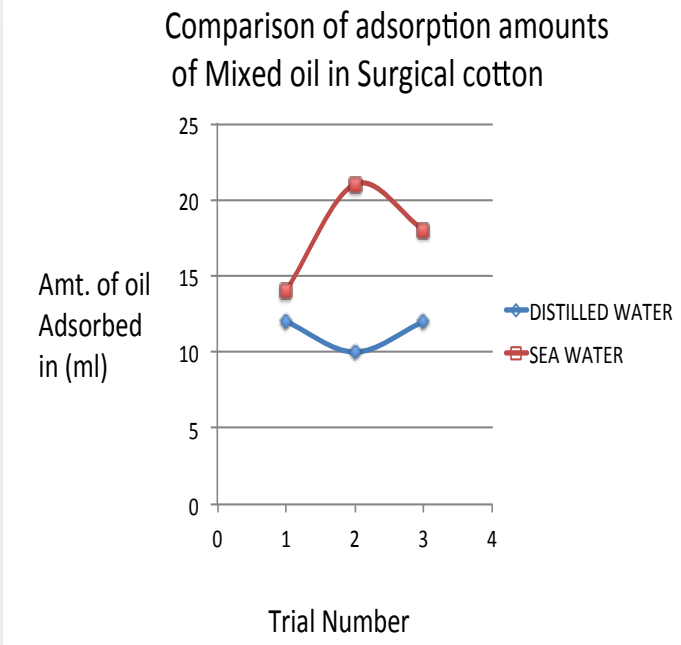

Fig-9: Amount of oil absorbed by surgical cotton

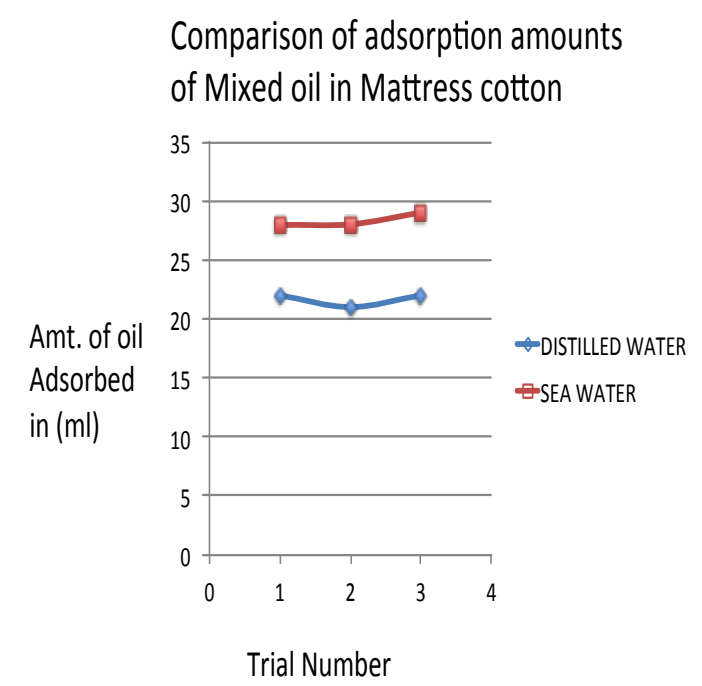

Fig-10: Amount of oil absorbed by mattress cotton

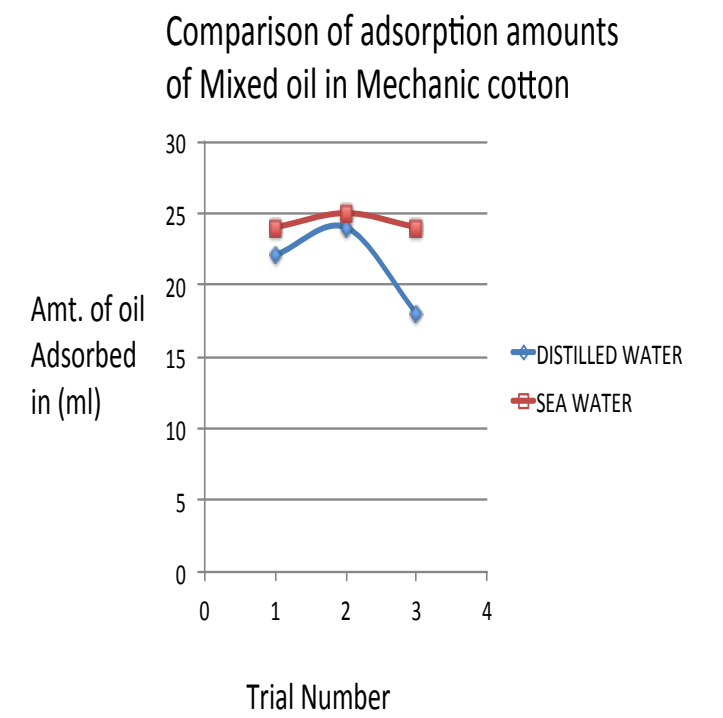

Fig-11: Amount of oil absorbed by Mechanic cotton 


\section{Comparison of adsorption amounts of Mixed oil in Seeded cotton}

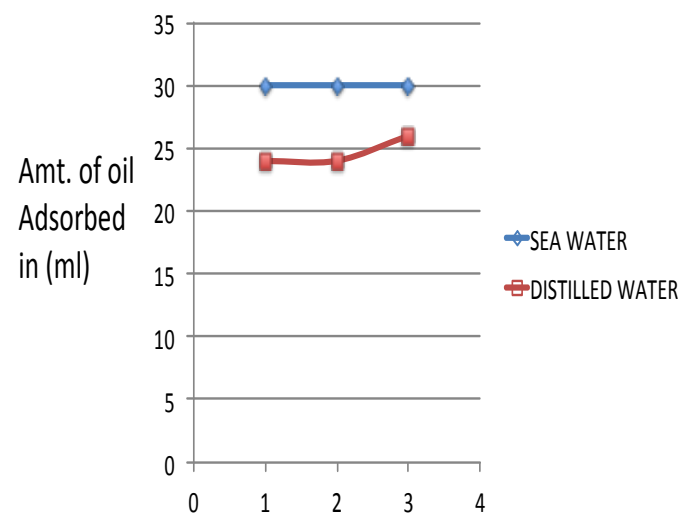

Trial Number

Fig-12: Amount of oil absorbed by seeded cotton

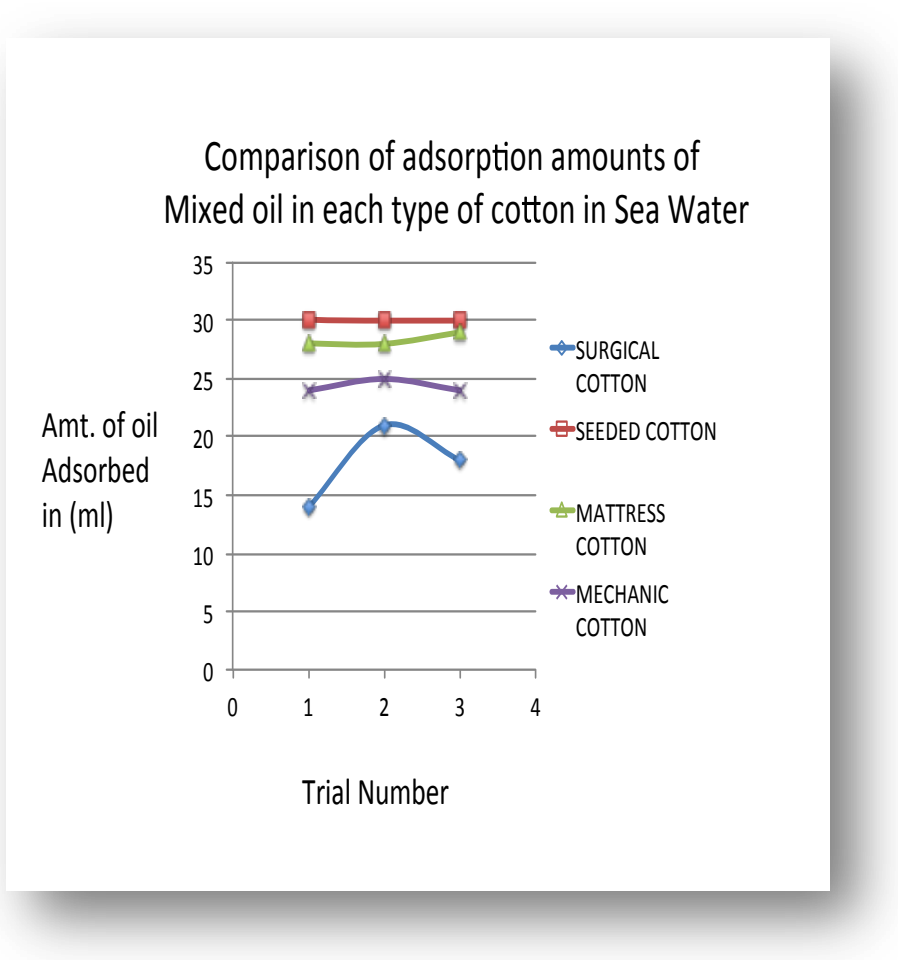

Fig-13: Comparison between different types of cotton

From figure 13 it has been observed that the amount of oil absorbed by seeded cotton and mattress cotton is more than the other grades of cotton used. This is due to the fact that the increase in the refining of cotton decreases adsorption capacity.

From the figures 10 to 12 ; it has been observed that the amount of oil absorbed in seawater is higher than the amount of oil that has been absorbed in distilled water. From the results obtained above the question as to why the amount of oil absorbed in seawater is higher than distilled water arises. To find the answer to this question salinity test has been conducted.

\section{EFFECT OF SALINITY ON ADSORPTION}

To perform the salinity test $1000 \mathrm{ml}$ of distilled water has been taken and to this 10 grams of rock salt had been added. Then a solution of salinity 10 has been prepared and the same above experimental procedure has been followed. The results obtained have been shown below. The test has been conducted on only seeded and mattress cotton as their adsorption capacities has been found out to be greater than the other two.

\section{Effect of Salinity (Seeded Cotton)}
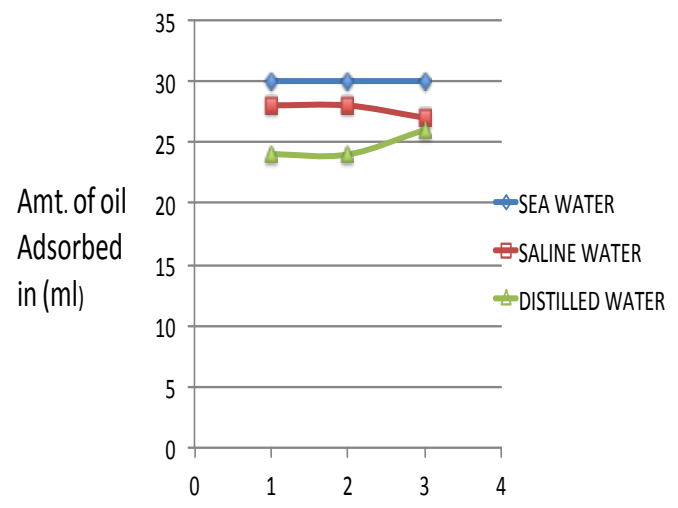

Trial Number

Fig-14: Effect of salinity (seeded cotton) 


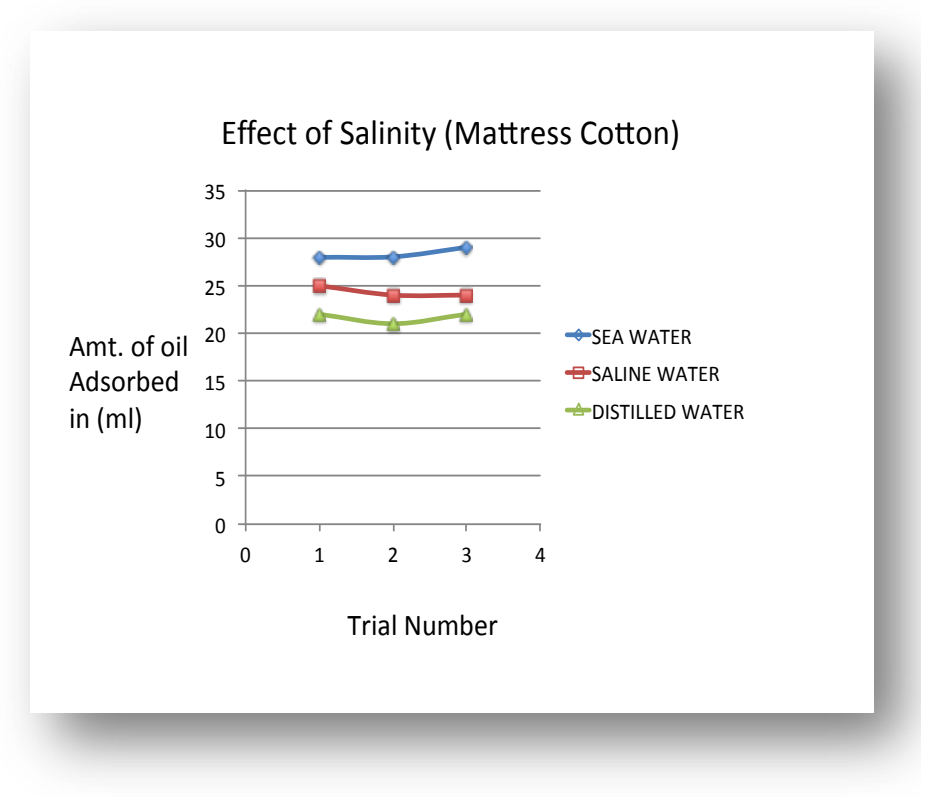

Fig-15: Effect of salinity (Mattress Cotton)

From the above graphs (figures $14 \& 15$ ) it can be noted that the absorption capacity of sea water is the highest followed by water of salinity 10 and finally distilled water. From this it has been concluded that salinity of water does play an important role in the absorption capacity of oil, as the increase in the salinity of water increases the absorption capacity.

\section{REUSABILITY OF COTTON}

To check whether the cotton was reusable or not the reusability test had been conducted. To perform this experiment the cotton used for the absorption experiment was manually squeezed to remove all the oil absorbed. Then this cotton was again used to perform the absorption test 2 times. This test has been performed for seeded and mattress cotton.

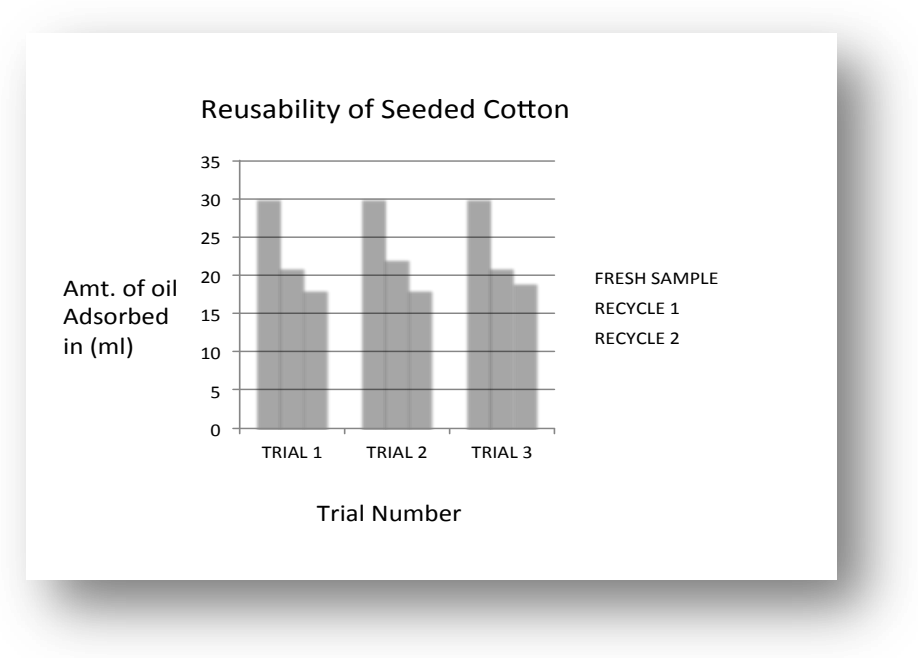

Fig-16: Reusability of seeded cotton

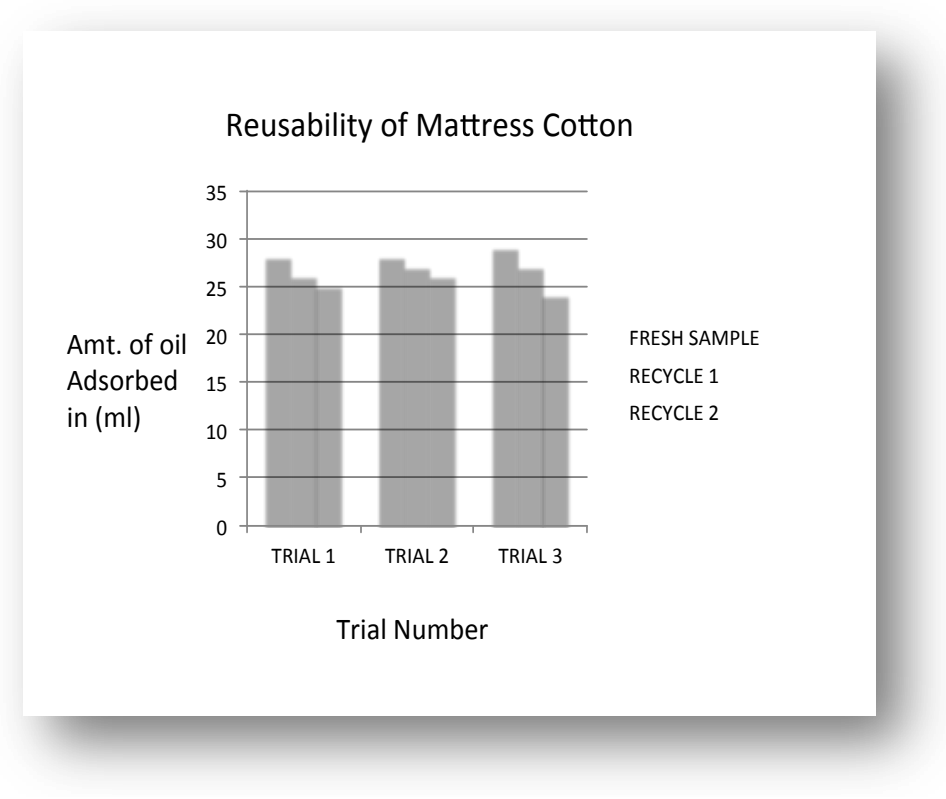

Fig-17: Reusability of Mattress cotton

Figure $16 \& 17$ shows that there is a decrease in oil sorption capacity due to repeated use of the cotton sample. On repeated use of the cotton sample there is a decrease in the adsorption capacity. The cotton fibers can be reused 3 to 5 times. It has been concluded from the above two graphs that though seeded cotton absorbs a greater amount of oil in the first try its recycling capacity drops to a considerable extent as compared to that of mattress cotton which has a better recycling capacity. The cotton sample can be reused if the absorbed crude oil fraction can be recovered by squeezing back to its original shape and size even if there is a tendency towards the decrease in oil adsorption on repeated use.

\section{CONCLUSIONS}

The recovered crude oil can be easily refined after which it can be recycled into other useful products. After extracting the oil out from the cotton fiber at the spill site, they can be reused multiple times by simply throwing them back onto the spill. Due to this very reason this latest research is turning so many eyes. It not only tells us about a better way to remove and recover oil after an oil spill but it also provides a solution which is cost effective. Hence one can draw upon the conclusion that a natural component can easily save our planet mother earth from such devastating man -made and natural disasters. 


\section{REFERENCES:}

[1] Mr. V. Ananth Kumar Thimmarusu (Associate Prof.) vakt.cbit@gmail.com

[2] Barua, Debojit, Jitu Buragohain, and Sarada Kanta Sarma. "Impact of Assam petroleum crude oil on the germination of four crude oil resistant species." Asian J Plant Sci Res 1 (2011): 68-76.

[3] Konno, A., and K. Izumiyama. "Theory and modeling of the interfacial tension force on the oil spreading under ice covers." Proceedings of the 16th IAHR International Symposium on Ice, Dunedin, New Zealand. 2002.

[4] Jakšić, Danilo, and Nikola Jakšić. "Porosity of the Flat Textiles."

\section{BIOGRAPHIES}

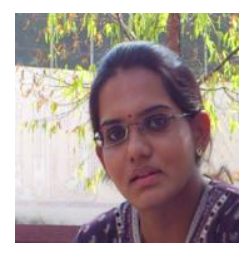

Jyothi Meher Nori, Student (Chem. Engg.)

Email: jyothinori@yahoo.com

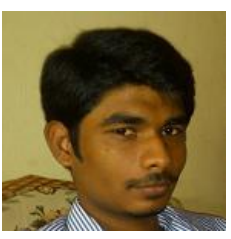

Borra Naga Santosh Anurag, Student (Chem. engg.). Email: anuragbns2193@gmail.com

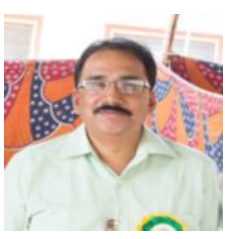

Mr. V. Ananth Kumar Thimmarusu, Associate Professor (Chem.engg.). Email: vakt.cbit@gmail.com 